\title{
ANALISIS CADANGAN PREMI ASURANSI JIWA DWIGUNA SEMIKONTINU DENGAN MENGGUNAKAN METODE ILLINOIS
}

\author{
HANDIKA WAHYU VIKRANTHA, DODI DEVIANTO, IZZATI RAHMI HG \\ Program Studi S1 Matematika, \\ Fakultas Matematika dan Ilmu Pengetahuan Alam, Universitas Andalas, \\ Kampus UNAND Limau Manis Padang, Indonesia. \\ email : vikrantha51@gmail.com
}

Diterima 14 Oktober 2019 Direvisi 21 Oktober 2019 Dipublikasikan 3 Desember 2019

\begin{abstract}
Abstrak. Asuransi jiwa dwiguna merupakan asuransi jiwa yang memiliki dua manfaat, yaitu sebagai proteksi jiwa dan juga sebagai tabungan. Santunan akan diberikan jika si tertanggung meninggal dalam jangka waktu pertanggungan ataupun hidup hingga akhir jangka waktu pertanggungan. Perhitungan asuransi jiwa terbagi atas dua yaitu secara diskrit dan kontinu. Perhitungan asuransi jiwa dwiguna semikontinu merupakan perhitungan asuransi jiwa dwiguna kontinu dengan menggunakan anuitas diskrit. Dalam perhitungan asuransi jiwa, perlu ditetapkan besar cadangan yang tepat. Apabila perhitungan yang dilakukan tidak tepat maka akan menyebabkan suatu kerugian bahkan kebangkrutan bagi perusahaan asuransi. Berdasarkan perhitungannya, cadangan dapat dihitung dengan dua metode yaitu metode prospektif dan retrospektif. Namun seringkali perhitungan cadangan dengan metode prospektif masih kurang tepat, sehingga selanjutnya digunakan metode modifikasi cadangan untuk mendapatkan nilai cadangan yang lebih sesuai. Salah satu metode modifikasi tersebut adalah metode Illinois. Pada penelitian ini terlihat perhitungan cadangan asuransi jiwa dwiguna semikontinu dengan metode Illinois memberikan besar cadangan yang cenderung lebih kecil daripada metode prospektif. Hal ini disebabkan perhitungan dengan metode Illinois turut mempertimbangkan pengeluaran-pengeluaran di awal tahun pertanggungan, sedangkan perhitungan dengan metode prospektif hanya berdasarkan premi kotor saja.
\end{abstract}

Kata Kunci: Asuransi jiwa dwiguna semikontinu, Cadangan, Metode Illinois

\section{Pendahuluan}

Pada kenyataannya, perjalanan hidup tak pernah semulus yang dibayangkan. Segala resiko dimasa yang akan datang dapat saja terjadi terhadap kehidupan seseorang seperti sakit, diberhentikan dari pekerjaan, dan bahkan kematian. Salah satu resiko yang mutlak akan terjadi adalah kematian. Oleh karena itu, diperlukan sebuah jaminan yang mampu meminimalkan resiko tersebut. Jaminan itu dapat dihadirkan berupa asuransi jiwa yang disediakan oleh berbagai macam perusahaan asuransi jiwa di Indonesia.

Dalam praktik sebenarnya, santunan akan dibayarkan sesaat setelah si tertanggung meninggal dunia dan pada umumnya pembayaran premi dilakukan secara 
berkala, inilah yang disebut sebagai asuransi jiwa kontinu. Menurut Nurani [7] jika perhitungan asuransi jiwa kontinu dilakukan dengan menggunakan anuitas diskrit maka disebut dengan asuransi jiwa semikontinu.

Jika tertanggung sudah membayarkan preminya, maka kewajiban dari perusahaan asuransi adalah menyiapkan cadangan untuk memenuhi santunan atau uang pertanggungan jika terjadi klaim. Menurut Futami [3] cadangan adalah besarnya uang yang ada pada perusahaan asuransi dalam jangka waktu pertanggungan.

Penentuan nilai cadangan premi dibagi menjadi dua jenis yaitu cadangan prospektif dan cadangan retrospektif [3]. Cadangan prospektif merupakan perhitungan cadangan berdasarkan nilai sekarang dari semua pengeluaran pada waktu yang akan datang dikurangi dengan nilai sekarang total pendapatan pada waktu yang akan datang untuk tiap pemegang polis. Sedangkan cadangan retrospektif merupakan perhitungan cadangan berdasarkan jumlah total pendapatan pada waktu yang lalu sampai saat dilakukan perhitungan cadangan dikurangi dengan jumlah pengeluaran diwaktu lalu untuk tiap pemegang polis.

Perhitungan cadangan premi dapat dimodifikasi untuk menghindari kerugian ditahun-tahun permulaan polis. Kerugian tersebut disebabkan oleh pengeluaran yang besar pada tahun permulaan polis. Ada beberapa metode perhitungan yang digunakan untuk memodifikasi cadangan premi salah satunya yaitu metode Illinois.

\section{Landasan Teori}

\subsection{Asuransi}

Berdasarkan Undang-Undang No.2 tahun 1992 tentang Usaha Perasuransian, asuransi adalah perjanjian antara dua pihak atau lebih, dimana pihak penanggung mengikatkan diri kepada tertanggung, dengan menerima premi asuransi, untuk memberikan penggantian kepada tertanggung karena kerugian, kerusakan, atau kehilangan keuntungan yang diharapkan, atau tanggung jawab hukum kepada pihak ketiga yang mungkin akan diderita tertanggung, yang timbul dari suatu peristiwa yang tidak pasti, atau untuk memberikan suatu pembayaran yang didasarkan atas meninggal atau hidupnya seseorang yang dipertanggungkan. Biaya yang dibayarkan oleh tertanggung kepada penanggung disebut premi. Biasanya biaya ditentukan oleh pihak penanggung untuk dana yang bisa diklaim dimasa depan, biaya administratif, dan keuntungan [10].

\subsection{Anuitas}

Anuitas adalah serangkaian pembayaran yang dilakukan dalam selang waktu yang sama. Anuitas hidup awal berjangka sebesar Rp.1 dengan bunga tahunan $i$ dan jangka pembayaran $n$ tahun dijabarkan sebagai berikut :

$$
\ddot{a}_{x: \bar{n} \mid}=\frac{N_{x}-N_{x+n}}{D_{x}} .
$$




\subsection{Asuransi Jiwa Semikontinu}

Pada asuransi jiwa kontinu nilai sekarang dari pembayaran sebesar Rp.1 untuk masing-masing orang yang meninggal di usia $x$ tahun didefinisikan sebagai berikut [7]:

$$
\bar{C}_{x}=v^{x+\frac{1}{2}} d_{x} .
$$

Selanjutnya jumlah nilai sekarang dari pembayaran sebesar Rp.1, untuk setiap orang yang meninggal dari usia $x$ tahun sampai akhir tabel mortalitas dinyatakan sebagai $[7]$ :

$$
\bar{M}_{x}=\sum_{i=x}^{w} \bar{C}_{i}=\bar{C}_{x}+\bar{C}_{x+1}+\cdots+\bar{C}_{w} .
$$

Asuransi jiwa dwiguna merupakan perpaduan antara asuransi jiwa berjangka dan asuransi dwiguna murni. Berikut ini akan dijabarkan perhitungan asuransi jiwa berjangka dengan uang pertanggungan dibayarkan $k$ kali. Perhitungan pembayaran uang pertanggungannya dilakukan tiap akhir jangka waktu $\frac{1}{k}, \frac{2}{k}, \cdots, 1$, sehingga nilai tengah saat pembayaran uang pertanggungan dibayarkan adalah $\frac{(1 / k)+(k / k)}{2}=$ $\frac{k+1}{2 k}$. Maka premi tunggal asuransi jiwa berjangka dijabarkan sebagai berikut :

$$
\begin{aligned}
& \bar{A}_{x: \overline{1} \mid}^{1}=v^{\frac{k+1}{2 k}} \frac{d_{x}}{l_{x}} \\
& \bar{A}_{x: \overline{2 \mid}}^{1}=v^{\frac{k+1}{2 k}} \frac{d_{x}}{l_{x}}+v^{\frac{k+1}{2 k}} v \frac{d_{x+1}}{l_{x}}
\end{aligned}
$$

dan seterusnya sehingga :

$$
\begin{aligned}
\bar{A}_{x: \bar{n} \mid}^{1} & =v^{\frac{k+1}{2 k}-1}\left(v \frac{d_{x}}{l_{x}}+v^{2} \frac{d_{x+1}}{l_{x}}+\cdots+v^{n} \frac{d_{x+n-1}}{l_{x}}\right) \\
& =(1+i)^{\frac{k-1}{2 k}} A_{x: \bar{n}}^{1}
\end{aligned}
$$

Untuk $k \rightarrow \infty$, maka premi tunggal asuransi jiwa berjangka untuk pembayaran santunan dibayarkan sesaat setelah tertanggung berusia $x$ meninggal dijabarkan sebagai berikut :

$$
\bar{A}_{x: \bar{n} \mid}^{1}=\lim _{k \rightarrow \infty}(1+i)^{\frac{k-1}{2 k}} A_{x: \bar{n} \mid}^{1}=\frac{\bar{M}_{x}-\bar{M}_{x+n}}{D_{x}}
$$

Selanjutnya premi tunggal asuransi jiwa dwiguna kontinu dituliskan sebagai berikut [5]:

$$
\bar{A}_{x: \overline{n \mid}}=A_{x: \bar{n} \mid}^{1}+{ }_{n} E_{x}=\frac{\bar{M}_{x}-\bar{M}_{x+n}+D_{x+n}}{D_{x}}
$$

Premi tahunan asuransi jiwa dwiguna semikontinu $n$ tahun dituliskan sebagai berikut [5]:

$$
P\left(\bar{A}_{x: \bar{n} \mid}\right)=\frac{\bar{A}_{x: \bar{n} \mid}}{\ddot{a}_{x: \bar{n} \mid}}=\frac{\bar{M}_{x}-\bar{M}_{x+n}+D_{x+n}}{N_{x}-N_{x+n}}
$$




\subsection{Metode Illinois}

Metode Illinois adalah suatu metode yang digunakan untuk menentukan cada-ngan premi suatu asuransi, dimana terdapat persyaratan yang harus terpenuhi yaitu nilai premi bersih tahunan yang dibayarkan tertanggung lebih besar dari nilai premi bersih tahunan asuransi jiwa seumur hidup dengan jangka pembayaran premi 20 tahun pada usia yang sama.

Metode Illinois menyatakan bahwa pada akhir jangka waktu pembayaran premi atau pada akhir jangka 20 tahun, yang manapun terjadi duluan, kedua cadangan harus sama.

$$
{ }_{t} V^{I}={ }_{k} V ; k=\min \{n, 20\} .
$$

Pada metode Illinois terdapat tiga nilai premi bersih yaitu:

1. $\alpha^{I}$ menyatakan premi bersih untuk tahun ke-1.

2. $\beta^{I}$ menyatakan premi bersih untuk tahun ke-2 sampai 20.

3. $P$ menyatakan premi bersih untuk tahun ke-21 dan seterusnya.

\section{Analisis Cadangan Premi Asuransi Jiwa Dwiguna Semikontinu dengan Menggunakan Metode Illinois}

\subsection{Menentukan Model Premi pada Metode Illinois}

Premi yang disesuaikan dengan metode illinois dapat dinyatakan dengan:

$$
\beta^{I}-\alpha^{I}={ }_{19} P_{x+1}-R \frac{C_{x}}{D_{x}},
$$

dimana $R$ adalah besar santunan dan $\frac{C_{x}}{D_{x}}$ adalah premi berjangka 1 tahun yang diperpanjang setiap tahunnya sampai waktu tertentu.

Untuk polis dengan pembayaran premi $>20$ tahun, persamaan umum metode Illinois-nya dinyatakan sebagai berikut [6]:

$$
\alpha^{I}+\beta^{I} a_{x: \overline{19 \mid}}+\left.P_{20}\right|_{n-20} \ddot{a}_{x}=P \ddot{a}_{x: \bar{n} \mid} .
$$

Karena $\ddot{a}_{x: \overline{n \mid}}=\ddot{a}_{x: \overline{20 \mid}}+\left.{ }_{20}\right|_{n-20} \ddot{a}_{x}$ maka :

$$
\alpha^{I}+\beta^{I} a_{x: \overline{19 \mid}}=P \ddot{a}_{x: \overline{20 \mid}} .
$$

Untuk polis dengan pembayaran premi $\leq 20$ tahun, maka persamaan umum metode Illinois-nya dapat dituliskan sebagai berikut :

$$
\alpha^{I}+\beta^{I} a_{x: \overline{k-1 \mid}}=P \ddot{a}_{x: \bar{k} \mid},
$$

dengan $k$ adalah nilai terkecil dari $n$ dan 20. Selanjutnya berdasarkan persamaan (3.1) maka:

$$
\beta^{I}=P+\frac{R\left({ }_{19} P_{x+1}\right)-R \frac{C_{x}}{D_{x}}}{\ddot{a}_{x: \bar{k} \mid}} .
$$




\subsection{Menentukan Cadangan Premi Asuransi Jiwa Dwiguna Semikontinu dengan Metode Illinois dan Metode Prospektif}

Berikut langkah-langkah dalam menentukan besar cadangan premi asuransi jiwa dwiguna semikontinu dengan menggunakan metode Illinois :

1. Menentukan besarnya cadangan prospektif pada asuransi jiwa dwiguna semikontinu.

Cadangan prospektif semikontinu akhir tahun ke- $t$ untuk seseorang berusia $x$ tahun dengan besar santunan Rp.1 pada asuransi dwiguna semikontinu $n$ tahun dan jangka pembayaran premi juga $h=n$ tahun adalah :

$$
{ }_{t} V\left(\bar{A}_{x: \overline{n \mid}}\right)=\bar{A}_{x+t: \overline{n-t \mid}}-P\left(\bar{A}_{x: \overline{n \mid}}\right) \ddot{a}_{x+t: \overline{n-t \mid}} .
$$

Selanjutnya besar cadangan prospektif akhir tahun ke- $t$ untuk seseorang berusia $x$ tahun dengan besar santunan Rp.1 pada asuransi jiwa dwiguna semikontinu $n$ tahun dan jangka pembayaran $h$ tahun adalah :

$$
{ }_{t}^{h} V\left(\bar{A}_{x: \overline{n \mid}}\right)= \begin{cases}\bar{A}_{x+t: \overline{n-t \mid}}-{ }_{h} P\left(\bar{A}_{x: \bar{n} \mid}\right) \ddot{a}_{x+t: \overline{h-t \mid}} & ; t \leq h<n \\ \bar{A}_{x+t: \overline{n-t \mid}} & ; h<t \leq n\end{cases}
$$

2. Menentukan besarnya cadangan premi pada asuransi jiwa dwiguna semikontinu berdasarkan metode Illinois.

a. Untuk asuransi jiwa dwiguna semikontinu $n$ tahun, dan jangka pembayaran $h<20$ tahun.

$$
{ }_{t}^{h} V^{I}\left(\bar{A}_{x: \overline{n \mid} \mid}\right)= \begin{cases}\bar{A}_{x+t: \overline{n-t} \mid}-\beta^{I}\left(\bar{A}_{x: \bar{n} \mid}\right) \ddot{a}_{x+t: \overline{h-t} \mid} & ; t \leq h<n \\ \bar{A}_{x+t: \overline{n-t \mid}} & ; h<t \leq n\end{cases}
$$

b. Untuk asuransi jiwa dwiguna semikontinu $n \leq 20$ tahun.

$$
{ }_{t} V^{I}\left(\bar{A}_{x: \bar{n} \mid}\right)=\bar{A}_{x+t: \overline{n-t} \mid}-\beta^{I}\left(\bar{A}_{x: \bar{n})}\right) \ddot{a}_{x+t: \overline{n-t} \mid}
$$

c. Untuk asuransi jiwa dwiguna semikontinu $n>20$ tahun, dan jangka pembayaran $20<h<n$.

$$
{ }_{t}^{h} V^{I}\left(\bar{A}_{x: \bar{n} \mid}\right)= \begin{cases}\bar{A}_{x+t: \overline{n-t} \mid}-\beta^{I}\left(\bar{A}_{x: \bar{n} \mid}\right) \ddot{a}_{x+t: \overline{20-t} \mid} & { }_{h} P\left(\bar{A}_{x: \bar{n} \mid}\right)\left[20-\left.t\right|_{h-20} \ddot{a}_{x+t}\right] \\ & ; t \leq 20 \\ \bar{A}_{x+t: \overline{n-t} \mid}-{ }_{h} P\left(\bar{A}_{x: \overline{n \mid} \mid}\right) \ddot{a}_{x+t: \overline{h-t} \mid} & ; 20<t \leq h \\ \bar{A}_{x+t: \overline{n-t} \mid} & ; h<t \leq n\end{cases}
$$

d. Untuk asuransi jiwa dwiguna semikontinu $n>20$ tahun.

$$
{ }_{t} V^{I}\left(\bar{A}_{x: \bar{n} \mid}\right)= \begin{cases}\bar{A}_{x+t: \overline{n-t} \mid}-\beta^{I}\left(\bar{A}_{x: \bar{n} \mid}\right) \ddot{a}_{x+t: \overline{20-t} \mid}- & P\left(\bar{A}_{x: \overline{n \mid}}\right)\left[20-\left.t\right|_{n-20} \ddot{a}_{x+t}\right] \\ & ; t \leq 20 \\ \bar{A}_{x+t: \overline{n-t} \mid}-P\left(\bar{A}_{x: \overline{n \mid}}\right) \ddot{a}_{x+t: \overline{n-t} \mid} & ; 20<t \leq n\end{cases}
$$




\section{Ilustrasi Kasus}

Rahmat seorang kepala cabang di sebuah perusahaan ekspedisi yang berusia 30 tahun akan mengikuti asuransi jiwa dwiguna semikontinu 25 tahun. Uang pertanggungan yang diharapkan adalah sebesar Rp.150.000.000,-. Jangka pembayaran premi yang diinginkan adalah 15 kali atau selama 15 tahun. Apabila nantinya Rahmat meninggal di dalam jangka waktu pertanggungan, maka uang pertanggungan akan dibayarkan di akhir tahun dengan tingkat suku bunga $10 \%$.

Akan ditentukan premi bersih asuransi jiwa dwiguna semikontinu 25 tahun, dengan jangka waktu pembayaran premi $(h)$ adalah 15 tahun, dan uang pertanggu$\operatorname{ngan}(R)$ adalah Rp.150.000.000,- yaitu:

$$
\begin{gathered}
{ }_{15} P\left(\bar{A}_{30: \overline{25 \mid}}\right)=R p .150 .000 .000 \frac{\bar{A}_{30: \overline{25 \mid}}}{\ddot{a}_{30: \overline{15}}}=R p .6 .531 .059,80512 \\
{ }_{20} P\left(\bar{A}_{30}\right)=R \frac{\bar{A}_{30}}{\ddot{a}_{30: \overline{20}}}=R p .3 .358 .782,14179
\end{gathered}
$$

Karena ${ }_{h} P\left(\bar{A}_{x: \bar{n}}\right)>{ }_{20} P\left(\bar{A}_{x}\right)$ maka memenuhi syarat untuk melakukan perhitungan cadangan premi dengan metode Illinois. Selanjutnya akan ditentukan besar cadangan premi asuransi jiwa dwiguna semikontinu dengan metode Illinois dan secara metode prospektif.

1. Besar cadangan premi asuransi jiwa dwiguna semikontinu secara metode $I l l i$ nois.

Besar cadangan asuransi jiwa dwiguna semikontinu secara metode Illinois untuk $t=1$ sampai dengan $t=15$.adalah :

$$
\begin{aligned}
& { }_{1}^{15} V^{I}\left(\bar{A}_{30: \overline{25 \mid}}\right)=\bar{A}_{31: \overline{24 \mid}}-\beta^{I}\left(\bar{A}_{30: \overline{25 \mid}}\right) \ddot{a}_{31: \overline{14} \mid}=\operatorname{Rp.5.048.769,2738} \\
& { }_{25}^{15} V^{I}\left(\bar{A}_{30: \overline{25 \mid}}\right)=\bar{A}_{55: \overline{0 \mid}}=\operatorname{Rp} 150.000 .000,00000
\end{aligned}
$$

Selengkapnya tentang besar cadangan asuransi jiwa dwiguna semikontinu secara metode Illinois selama 25 tahun dapat dilihat di Tabel 4.3.1.

2. Besar cadangan premi asuransi jiwa dwiguna semikontinu secara metode prospektif.

Akan ditentukan besar cadangan premi asuransi jiwa dwiguna secara metode prospektif untuk $t=1$ sampai dengan $t=15$ yaitu:

$$
\begin{aligned}
{ }_{1}^{15} V^{I}\left(\bar{A}_{30: \overline{25 \mid}}\right) & =\bar{A}_{31: \overline{24} \mid}-\left({ }_{15} P\left(\bar{A}_{30: \overline{25 \mid}}\right)\right) \ddot{a}_{31: \overline{14} \mid}=\text { Rp.6.579.703, 81918 } \\
& \vdots \\
{ }_{25}^{15} V^{I}\left(\bar{A}_{30: \overline{25 \mid}}\right) & =\bar{A}_{55: \overline{0} \mid}=\operatorname{Rp} .150 .000 .000,00000
\end{aligned}
$$

Selanjutnya kita akan melihat bagaimana perbandingan besar cadangan premi asuransi jiwa dwiguna semikontinu berdasarkan metode Illinois dan metode prospektif pada Gambar 1. 
Tabel 1. Cadangan Asuransi Jiwa Dwiguna Semikontinu dengan Metode Illinois selama $n=25$ tahun dengan $h=15$ tahun

\begin{tabular}{|c|c|c|}
\hline \multicolumn{3}{|c|}{ Besar Cadangan ( Rupiah ) } \\
\hline Th & Premi Bersih & Cadangan secara Metode Illinois \\
\hline 1 & $3.198 .751,17734$ & $5.048 .769,27380$ \\
\hline 2 & $6.659 .616,89179$ & $11.884 .723,61078$ \\
\hline 3 & $6.659 .616,89179$ & $18.893 .095,36568$ \\
\hline 4 & $6.659 .616,89179$ & $26.081 .400,35812$ \\
\hline 5 & $6.659 .616,89179$ & $33.453 .198,03025$ \\
\hline 6 & $6.659 .616,89179$ & $41.010 .040,59250$ \\
\hline 7 & $6.659 .616,89179$ & $48.754 .229,22720$ \\
\hline 8 & $6.659 .616,89179$ & $56.689 .877,23576$ \\
\hline 9 & $6.659 .616,89179$ & $64.822 .668,02117$ \\
\hline 10 & $6.659 .616,89179$ & $73.156 .210,62087$ \\
\hline 11 & $6.659 .616,89179$ & $81.696 .061,29467$ \\
\hline 12 & $6.659 .616,89179$ & $90.448 .135,03219$ \\
\hline 13 & $6.659 .616,89179$ & $99.422 .609,40091$ \\
\hline
\end{tabular}

\begin{tabular}{|c|c|c|}
\hline Th & Premi Bersih & Cadangan secara Metode Illinois \\
\hline 14 & $6.659 .616,89179$ & $108.628 .340,36912$ \\
\hline 15 & $6.659 .616,89179$ & $118.074 .350,80880$ \\
\hline 16 & - & $120.925 .376,65409$ \\
\hline 17 & - & $123.842 .720,41888$ \\
\hline 18 & - & $126.828 .721,08747$ \\
\hline 19 & - & $129.886 .418,89628$ \\
\hline 20 & - & $133.019 .608,07181$ \\
\hline 21 & - & $136.232 .040,11404$ \\
\hline 22 & - & $139.528 .714,10099$ \\
\hline 23 & - & $142.916 .422,93344$ \\
\hline 24 & - & $146.403 .804,24000$ \\
\hline 25 & - & $150.000 .000,00000$ \\
\hline
\end{tabular}

Dari tahun ke-1 sampai tahun ke-15, perbedaan atau selisih nilai cadangan pertahunnya lebih besar dibandingkan dengan selisih cadangan pertahun dari tahun ke-16 sampai tahun ke-25. Hal ini terjadi karena pembayaran premi yang dilakukan si tertanggung hanya sampai pada tahun ke-15, dan pada tahun ke-16 dan seterusnya perusahaan asuransi tidak lagi mendapat pemasukan dari pembayaran premi.

\section{Kesimpulan}

Perhitungan cadangan premi asuransi jiwa dwiguna semikontinu dengan metode Illinois akan menghasilkan besar cadangan yang cenderung lebih kecil dibandingkan dengan metode prospektif dikarenakan pada perhitungan cadangan dengan 


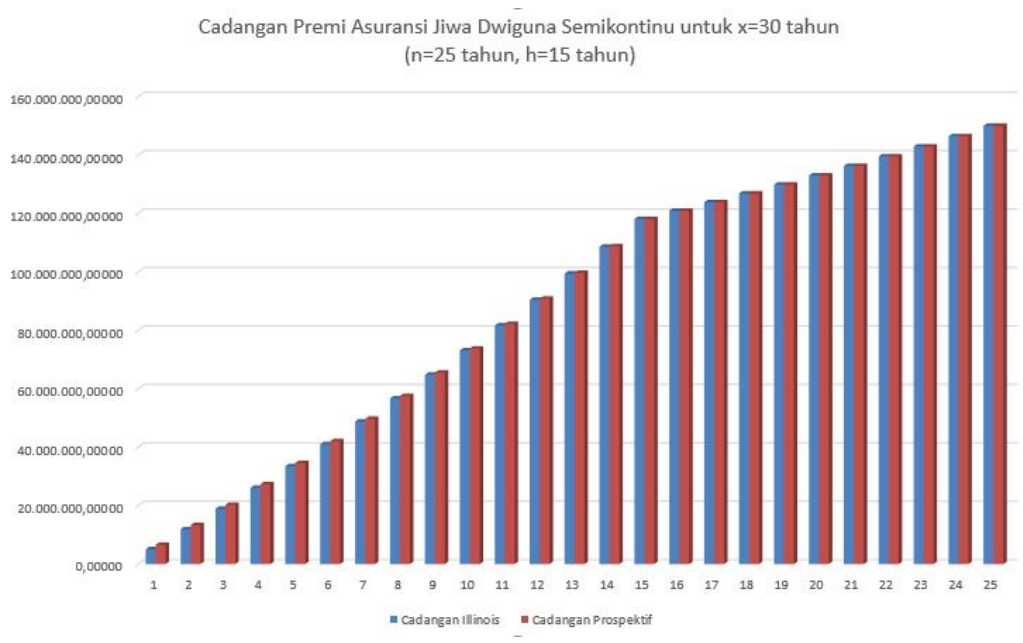

Gambar 1. Besar Cadangan Premi Asuransi Jiwa Dwiguna Semikontinu untuk x=30 tahun, n=25 tahun dan $\mathrm{h}=15$ tahun dengan Metode Illinois dan Metode Prospektif

metode Illinois turut memperhitungkan biaya-biaya operasional lain, sehingga hal ini mampu mencegah perusahaan asuransi mengalami kerugian bahkan kebangkrutan, sedangkan perhitungan dengan metode prospektif hanya berdasarkan premi kotor.

\section{Daftar Pustaka}

[1] Bowers, N.L., H.U. Gerber, J.C. Hickman, D.A. Jones,\& C.J. Nesbitt. 1997. Actuarial Mathematics. The Society Of Actuaries, United States of America.

[2] Darmawi, Herman. 2004. Manajemen Asuransi. Bumi Aksara, Jakarta.

[3] Futami,T. 1993. Matematika Asuransi Jiwa, Bagian I. Ter. Dari Seimei Hoken Sugaku, Jokan(92 Revision) oleh Herliyanto, Gatot. Incorporated Foundation Oreintal Life Insurance Cultural development Center, Japan.

[4] Futami,T. 1994. Matematika Asuransi Jiwa, Bagian II. Ter. Dari Seimei Hoken Sugaku, Gekan (92 Revision) oleh Herliyanto, Gatot. Incorporated Foundation Oriental Life Insurance Cultural development Center, Japan.

[5] Jordan Jr, C.W. 1991. Society of Actuaries Textbook on Life Contingencies. Second Edition. The Society of Actuaris, Chicago.

[6] Larson, Robert E., Erwin A.Gaumnitz. 1962. Life Insurance Mathematics. John Wiley \& Sons, London.

[7] Novri, Ferdy. 2016. Penentuan Besar Cadangan pada Asuransi Jiwa Bersama Dwiguna dengan Metode Illinois. Universitas Andalas, Padang.

[8] Nurani, Bening Bela. 2015. Asuransi Jiwa Kontinu. Universitas Brawijaya, Malang.

[9] Ramadhani, Kiki. 2019. Pengaruh Penggunaan Hukum Mortalitas Gompertz Pada Penentuan Besarnya Asuransi Jiwa Dwiguna Dengan Metode Full Preliminary Term. Universitas Andalas, Padang.

[10] Undang-Undang Republik Indonesia Tahun 1992 tentang Usaha Perasuransian. 1992. Armas Duta Jaya, Jakarta. 